\title{
FIRE INCREASES INVASIVE SPREAD OF MOLINIA CAERULEA MAINLY THROUGH CHANGES IN DEMOGRAPHIC PARAMETERS
}

\author{
Hans Jacquemyn, ${ }^{1,4}$ Rein Brys, ${ }^{1,2}$ And Michael G. Neubert ${ }^{3}$ \\ ${ }^{1}$ Laboratory for Forest, Nature and Landscape Research, Catholic University of Leuven, Vital Decosterstraat 102, \\ B-3000 Leuven, Belgium \\ ${ }^{2}$ Institute of Nature Conservation, Kliniekstraat 25, B-1070 Brussels, Belgium \\ ${ }^{3}$ Biology Department, MS-34, Woods Hole Oceanographic Institution, Woods Hole, Massachusetts 02543-1049 USA
}

\begin{abstract}
We investigated the effects of fire on population growth rate and invasive spread of the perennial tussock grass Molinia caerulea. During the last decades, this species has invaded heathland communities in Western Europe, replacing typical heathland species such as Calluna vulgaris and Erica tetralix. M. caerulea is considered a major threat to heathland conservation. In 1996, a large and unintended fire destroyed almost one-third of the Kalmthoutse Heide, a large heathland area in northern Belgium. To study the impact of this fire on the population dynamics and invasive spread of $M$. caerulea, permanent monitoring plots were established both in burned and unburned heathland. The fate of each M. caerulea individual in these plots was monitored over four years (1997-2000). Patterns of seed dispersal were inferred from a seed germination experiment using soil cores sampled one month after seed rain at different distances from seed-producing plants. Based on these measures, we calculated projected rates of spread for $M$. caerulea in burned and unburned heathland. Elasticity and sensitivity analyses were used to determine vital rates that contributed most to population growth rate, and invasion speed. Invasion speed was, on average, three times larger in burned compared to unburned plots. Dispersal distances on the other hand, were not significantly different between burned and unburned plots indicating that differences in invasive spread were mainly due to differences in demography. Elasticities for fecundity and growth of seedlings and juveniles were higher for burned than for unburned plots, whereas elasticities for survival were higher in unburned plots. Finally, a life table response experiment (LTRE) analysis revealed that the effect of fire was mainly contributed by increases in sexual reproduction (seed production and germination) and growth of seedlings and juveniles. Our results clearly showed increased invasive spread of $M$. caerulea after fire, and call for active management guidelines to prevent further encroachment of the species and to reduce the probability of large, accidental fires in the future. Mowing of resprouted plants before flowering is the obvious management tactic to halt massive invasive spread of the species after fire.
\end{abstract}

Key words: disturbance; elasticity; fire; integrodifference equations; invasive spread; LTRE; matrix population model; Molinia caerulea; sensitivity.

\section{INTRODUCTION}

European heathlands are generally known as low productivity ecosystems characterized by dominance of typical dwarf shrub species such as Calluna vulgaris and Erica tetralix. Traditionally, these heathland systems were maintained by small-scale land use practices such as sod cutting, grazing by sheep, or controlled burning in winter (Gimingham 1972). During the last decades, however, typical heathland species have been gradually replaced by more competitive species such as Molinia caerulea and Deschampsia flexuosa. In particular, the distribution and abundance of $M$. caerulea has increased in Western Europe to such an extent that $M$. caerulea has become the dominant species in many

Manuscript received 19 November 2004; revised 8 March 2005; accepted 22 March 2005; Corresponding Editor: C. L. Boggs.

${ }^{4}$ E-mail: hans.jacquemyn@biw.kuleuven.be heathland communities (e.g., Hansen 1976, Berendse et al. 1994, Chambers et al. 1999). Increased nitrogen deposition and changes in management have been proposed as the main causes for this shift in species composition (Aerts and De Caluwe 1989, Aerts 1993, Berendse et al. 1994, Limpens et al. 2003, Tomassen et al. 2003). As a result, $M$. caerulea encroachment is considered a major threat to heathland conservation in Western Europe (Marrs et al. 2004).

As $M$. caerulea is a deciduous grass species that produces large amounts of litter each year, this shift from fields dominated by $C$. vulgaris to those dominated by $M$. caerulea has resulted in several large, mostly unintended fires, especially in dry heathlands. Fire may dramatically affect population dynamics of plants (reviewed in Noble and Slatyer 1980). Indeed, for most species, population dynamics have been shown to be very different in burned and unburned sites (e.g., Silva et al. 1991, Canales et al. 1994, Caswell 
and Kaye 2001, Garnier and Dajoz 2001a, Kaye et al. 2001, Satterthwaite et al. 2002, Quintana-Ascencio et al. 2003, Menges and Quintana-Ascencio 2004). Fire has been shown to increase population growth rates by increasing seed production (McConnell and Menges 2002), seed germination rates (Canales et al. 1994, Menges and Dolan 1998), or growth (Lamont and Wiens 2003). Moreover, because of changes in seed production rates and vegetation structure, fire can also be expected to alter the mean seed dispersal distance (Nathan and Muller-Landau 2000) and hence the invasion speed of the species (Neubert and Caswell 2000, Caswell et al. 2003), although at present this has not yet been rigorously investigated.

To give a full account of the relative importance of dispersal and demographic parameters in determining invasive spread of species and how these are affected by disturbances such as fire, one needs to incorporate both parameters into one single measure. A measure that integrates dispersal and population vital rates is the invasion speed, $c^{*}$ (Neubert and Caswell 2000, Caswell et al. 2003). Like population growth rate, $\lambda$, invasion speed allows calculation of sensitivity and elasticity measures, which determine how invasion speed would respond to changes in demographic and dispersal parameters, and life table response experiments (LTRE), which determine how differences in model parameters between different populations contribute to differences in their invasion speeds. Because prospective perturbation analyses of $c^{*}$ identify the life cycle stages that are most important in determining population growth rate and invasive spread (see Caswell 2000), they are very useful in resolving which stages are crucial to attack when attempting to slow invasive spread (Fagan et al. 2002). Furthermore, methods to model the impact of temporally heterogeneous environments on invasion wave speed have been developed (Neubert et al. 2000). The latter allow calculating timeaveraged invasion rates in periodic environments and expected time-averaged invasion rates in stochastic environments (Neubert et al. 2000, Neubert and Parker 2004).

In this study, we examined how fire affected dispersal, population dynamics, and invasion speed of the perennial tussock-forming grass $M$. caerulea in the Kalmthoutse Heide, a relatively large heathland area in the northern part of Belgium. In April 1996, a large and unintended fire burned almost one-third of the area. In 1997, burned M. caerulea plants had resprouted and produced seeds. Detailed demographic data were collected for four years between 1997 and 2000, whereas seed dispersal distances were inferred from a seed germination experiment using soil cores sampled one month after seed rain in 1997. More specifically, we investigated the following questions: (1) How does fire affect population growth rate and invasion speed of $M$. caerulea in dry heathland? (2) Which vital rates are most important in determining population growth rates and which parameters (demographic or dispersal) are most important in determining invasion speed? (3) What kind of management strategies can be deduced from the observed patterns of invasion?

\section{Methods \\ Study plant}

Molinia caerulea (purple moor-grass) is a tall, perennial grass species that occurs throughout much of Europe and that extends its distribution to North Africa, Caucasus, and Siberia (Taylor et al. 2001). The species occupies a wide range of habitats (ranging from forests to grasslands to heathlands) and soil types (ranging from dry acid sands to wet calcareous bogs). In Belgium, the distribution of $M$. caerulea is more or less restricted to heathland areas and pine plantations. Molinia caerulea forms swards or large tussocks from 8 to $20 \mathrm{~cm}$ (sometimes $>30 \mathrm{~cm}$ ) in diameter at the base. It has an enormous root system that forms a dense tangle at the top and that penetrates to a great depth $(>100 \mathrm{~cm}$; Aerts 1993). Because of its large root system, the species is well adapted to survive intense fires.

In contrast to many other grass species, the tufted growth form shows very little lateral vegetative spread, making spatial spread and colonization of vacant sites highly dependent on sexual reproduction and seed set. Flowers are wind pollinated and seeds are dispersed by wind. Mean seed production per plant is generally high (>20000 seeds per flowering plant; Bruggink 1993, Brys et al. 2005). Seeds are relatively small, have a mean air-dry mass of $0.53 \mathrm{mg}$ (Grime et al. 1981), and they are readily able to colonize bare ground (Taylor et al. 2001).

\section{Study site}

This study was carried out at the Kalmthoutse Heide, a relatively large heathland area (1020 ha) situated in the northern part of Belgium (near Antwerp). The soil type can be characterized as a humus podsol. An intense and large fire on 24 April 1996 burned nearly one-third of the area (see Plate 1). Before the fire had burned the area, the vegetation at the study site was characterized by relatively high dominance of Calluna vulgaris, whereas $M$. caerulea occurred in isolated tussocks. Other plant species occasionally observed were Erica tetralix, Rynchospora alba, Festuca ovina subsp. tenuifolia, Carex pilulifera, and the mosses Campylopus introflexus, Cladonia portentosa, Cladonia floerkeana, and Hypnum jutlandicum. By the year following the fire, burned $M$. caerulea plants had resprouted and produced seeds.

\section{Seed dispersal distances}

Seed dispersal distances were determined indirectly by investigating spatial distribution patterns of viable seeds in the soil. Therefore, the upper part of the soil $(5 \mathrm{~cm})$ was sampled around 16 mature individuals, 


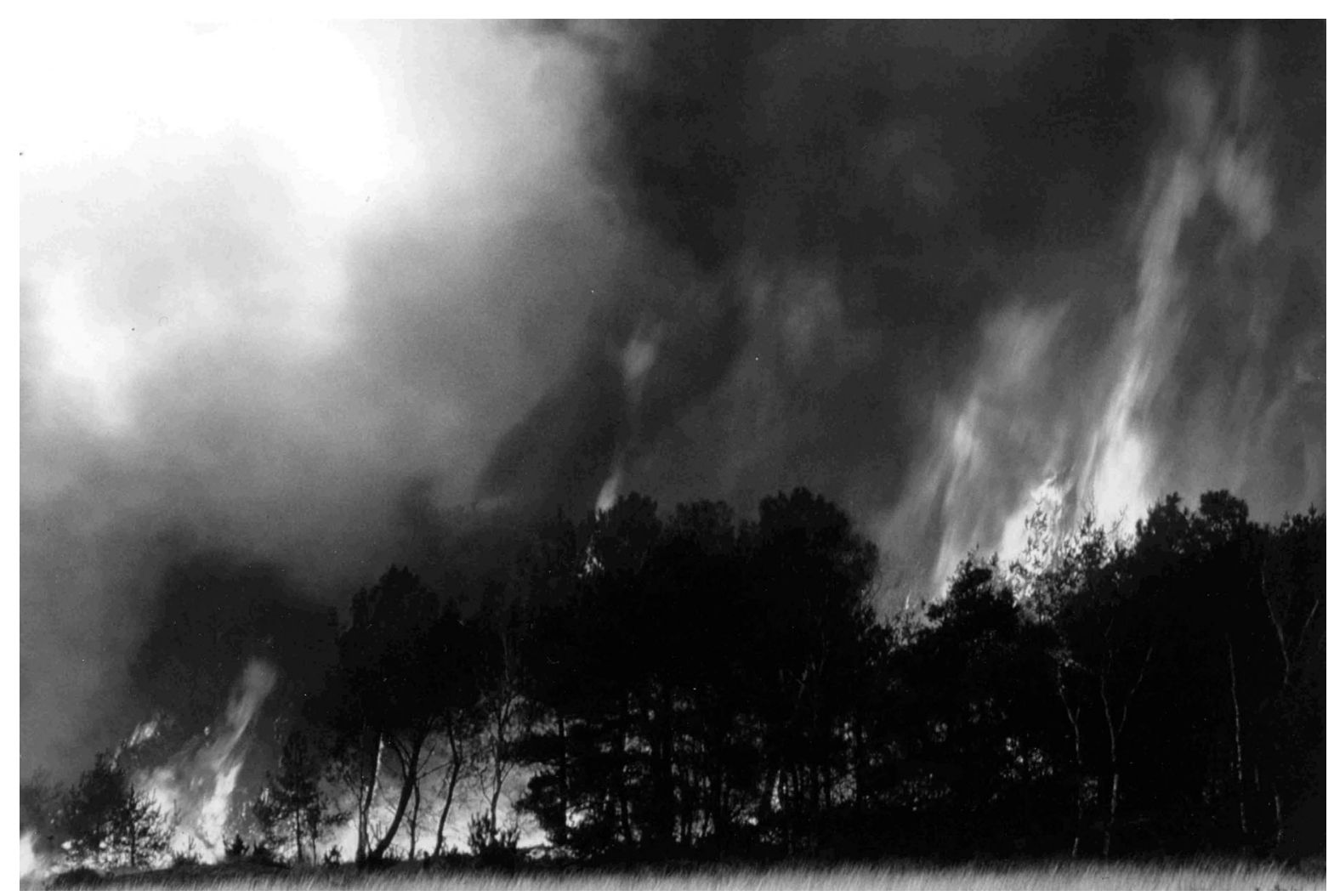

Plate 1. The high-intensity fire that in April 1996 destroyed almost one-third of the Kalmthoutse Heide. Photo credit: Marc Slootmackers.

eight in burned and eight in unburned heathland. As M. caerulea has only a shallow seed bank and sampling took place in November (i.e., one month after seed set), the sampled seeds almost certainly originated from the current year's seed set. This method was preferred above the seed trap method, because $M$. caerulea produces large amounts of unviable seeds (due to smut fungus and post-dispersal seed predation; R. Brys, personal observation), which may lead to overestimation of seed dispersal distances.

For each individual, several soil cores were taken at the main angles $\left(0^{\circ}, 90^{\circ}, 180^{\circ}\right.$, and $\left.270^{\circ}\right)$ and at regular distances from the parent plant $(0-50 \mathrm{~cm}, 50-100 \mathrm{~cm}$, $100-200 \mathrm{~cm}, 200-300 \mathrm{~cm}$, and $300-400 \mathrm{~cm})$. Soil cores were taken with a soil bore with a diameter of $3.5 \mathrm{~cm}$. For each angle and each interval, soil samples were regularly spaced within the different intervals. After collection, soil cores were washed through a coarse (4 mm mesh width) and fine $(0.2 \mathrm{~mm}$ mesh width) sieve. The concentrated samples were spread out into a layer of maximum $2 \mathrm{~mm}$ thickness on $15 \times$ $15 \mathrm{~cm}$ trays filled with sterilized potting soil. Seeds were germinated in laboratory conditions ( $16 \mathrm{~h}$ daylight, $25^{\circ} \mathrm{C} ; 8 \mathrm{~h}$ dark, $16^{\circ} \mathrm{C}$ ) for six weeks, after which germination had ceased. For each individual and for each distance class, soil cores were pooled to obtain mean seed densities at particular distances from the parent plant.

\section{Demographic data and construction of projection matrices}

In 1997, eight $2 \times 2 \mathrm{~m}^{2}$ permanent monitoring plots (four in burned and four in unburned heathland) were established. Based on soil and vegetation maps (De Blust and Slootmaekers 1997) and aerial photographs, it was ascertained that the study was performed on a large, homogenous site that showed no differences in soil conditions and vegetation characteristics prior to burning. Plots were laid out in pairs (one in burned and one in unburned heathland), which allowed investigation of the importance of local site conditions on the effects of fire on population dynamics. From 1997 until 2000, all plants within each plot were monitored annually in late September. At that time, seedlings had emerged and were clearly visible. Individual plants were not tagged, but mapped using a $10 \times 10 \mathrm{~cm}^{2}$; grid. In this way, the fate of each individual was recorded in each plot in each year. At the same time, basal diameter of adult, seed-producing plants was also recorded.

A biological stage classification based on plant size and reproductive status was used to classify each $M$. 


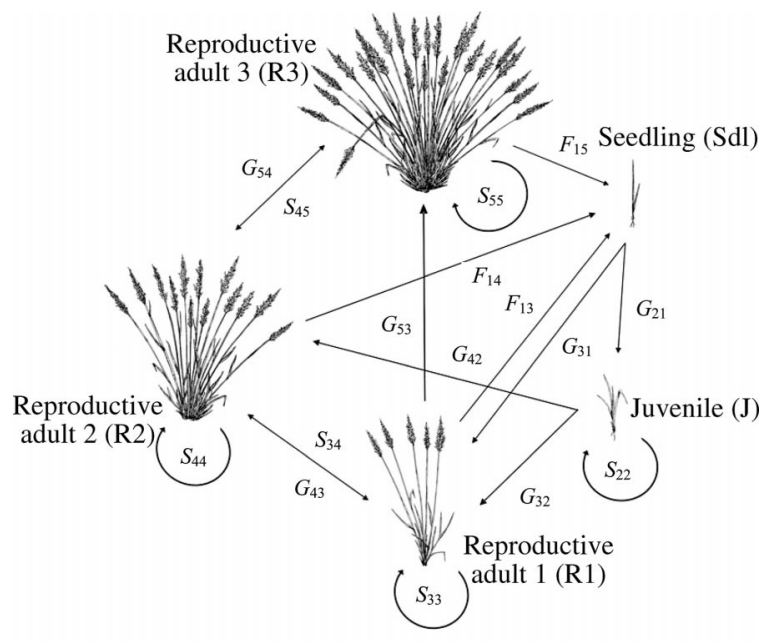

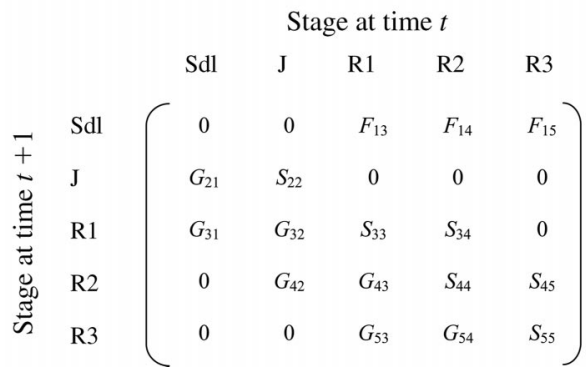

FIG. 1. Life cycle graph of Molinia caerulea and the associated population projection matrix. Arrows represent transitions between stages, and letters show the connection between each transition and its corresponding matrix entry. Matrix entries are subdivided in fecundity $(F$, number of seedlings per reproductive adult), growth ( $G$, transition to higher stages), and survival ( $S$, remaining at the same stage or retrogression to a lower stage).

caerulea individual into one of five classes: seedlings $(\mathrm{Sdl})$, juveniles $(\mathrm{J})$, small reproductive plants with rosette diameter $<12.5 \mathrm{~cm}$ (R1), medium-sized reproductive plants with rosette diameter 12.5 to $<25 \mathrm{~cm}$ (R2), and large reproductive plants with rosette diameter $>25 \mathrm{~cm}$ (R3). Seedlings were defined as first year vegetative plants, whereas juveniles consisted of all nonseedling vegetative plants older than one year. The life cycle graph of $M$. caerulea is represented in Fig. 1.

Transition matrices were constructed from these data for each plot in each year. The "anonymous reproduction method" (Caswell 2001) was used to estimate stage-specific fertility. Therefore, the total number of seedlings in year $t+1$ was multiplied by the proportion of viable seeds produced by each stage in year $t$. Both for plants from burned and unburned plots, plant size (basal diameter) was significantly related to seed production (one-way ANOVA, $F=12.76, P<0.001$ and $F=6.38, P=0.004$ for plants from burned and unburned plots, respectively).

\section{Data analysis}

Averaged demographic matrices rather than the individual matrices were used to determine population growth rate and invasion speed. Each averaged matrix was a weighted mean of the matrices for all the plotyear combinations corresponding to that plot. Following Caswell and Kaye (2001), the weight for all elements within a column was the sample size from which that column was estimated. From these matrices, we calculated the asymptotic growth rate, $\lambda$, following methods outlined in Caswell (2001).

In order to assess whether fire affected population growth rates, a nonparametric randomization procedure based on permutations of individual life history was used. Since plots were sampled in pairs (one in burned and one in unburned heathland), for each pair individual life histories were randomly permuted between the burned and unburned plot, new matrices were constructed, and the population growth rate was calculated. This procedure was repeated 2000 times to obtain a frequency distribution of population growth rates under the null hypothesis of no difference between burned and unburned plots. Finally, the observed growth rate was compared with those obtained by randomly permuting individuals.

Elasticity analysis was conducted to determine life cycle transitions that have the largest impact on $\lambda$ (de Kroon et al. 1986). Following Parker (2000), elasticities were summed for each column, excluding fecundity, to generate composite elasticities for the fate of seedlings, juveniles, and small, medium, and large reproductive adults. Additionally, a composite elasticity for fecundity was also generated. In this way, the elasticity structure for burned and unburned plots was represented.

Invasion speed was obtained following methods outlined in Neubert and Caswell (2000). To briefly review, this model assumes that population spread is the net result of two processes: population growth and dispersal. Assume that we have divided the population into $m$ life history stages. Let $n_{i}(y, t)$ be the population density of stage $i$ at location $y$ and time $t$, and let $b_{i j}\left(n_{1}(y\right.$, $\left.t), n_{2}(y, t), \ldots n_{m}(y, t)\right)$ be the per capita production of stage $i$ individuals at time $t+1$ by stage $j$ individuals at time $t$. Finally, let $k_{i j}(x-y) d x$ be the fraction of stage $i$ individuals produced by stage $j$ individuals at $y$ that disperse into the interval $(x, x+d x)$. If there is no dispersal during a given transition, the associated kernel is the Dirac delta function $\delta(x-y)$, a function that (very roughly speaking) is zero if $x \neq y$, is infinite when $x=y$, and integrates to 1 . That is, with probability 1 , such an individual stays where it is.

For each stage $i$, we then have

$$
\begin{aligned}
& n_{i}(x, t+1) \\
& \quad=\int_{-\infty}^{\infty} \sum_{j=1}^{m} k_{i j}(x-y) b_{i j}\left[n_{1}(y, t), \ldots, n_{m}(y, t)\right] n_{j}(y, t) d y
\end{aligned}
$$

or in matrix notation 


$$
\mathbf{n}(x, t+1)=\int_{-\infty}^{\infty}\left[\mathbf{K}(x-y) \circ \mathbf{B}_{n(y, t)}\right] \mathbf{n}(y, t) d y .
$$

The symbol "o" stands for the Hadamard product (Horn and Johnson 1985), wherein multiplication is computed element by element. For M. caerulea, we assumed that $\mathbf{K}$ had the form

$$
\mathbf{K}(x)=\left[\begin{array}{lllll}
\delta(x) & \delta(x) & k(x) & k(x) & k(x) \\
\delta(x) & \delta(x) & \delta(x) & \delta(x) & \delta(x) \\
\delta(x) & \delta(x) & \delta(x) & \delta(x) & \delta(x) \\
\delta(x) & \delta(x) & \delta(x) & \delta(x) & \delta(x) \\
\delta(x) & \delta(x) & \delta(x) & \delta(x) & \delta(x)
\end{array}\right] .
$$

That is, we assumed that dispersal only occurred directly after the production of seeds by adults, and that the dispersal kernel was the same for all transitions.

Under biologically reasonable conditions on the matrix $\mathbf{B}_{\mathrm{n}}$ (including nonnegativity, primitivity, and the absence of Allee effects [Lui 1989, Neubert and Caswell 2000]), the rate of spread of the population is given by

$$
c^{*}=\min _{s>0}\left[\frac{1}{s} \log \rho_{1}(s)\right]
$$

where $\rho_{1}(s)$ is the largest eigenvalue of the matrix $\mathbf{M}(s)$ $\circ \mathbf{A}, \mathbf{A}=\mathbf{B}_{0}$, and the $i, j$ element of the matrix $\mathbf{M}(s)$ is the moment generating function of the kernel $k_{i j}(x)$, i.e.,

$$
m_{i j}(s)=\int_{-\infty}^{\infty} k_{i j}(x) e^{s x} d x
$$

We use $s^{*}$ to denote the value of $s$ that produces the minimum in (4).

The sensitivity of the rate of spread, $c^{*}$, to changes in the entries of $\mathbf{A}$ is given by (Neubert and Caswell 2000):

$$
\frac{\partial c^{*}}{\partial a_{i j}}=\frac{m_{i j}\left(s^{*}\right)}{s^{*} \rho_{1}} \frac{v_{i} w_{j}}{\langle\mathbf{v}, \mathbf{w}\rangle}
$$

where $\langle\cdot\rangle$ denotes the scalar product, $\rho_{1}$ is the dominant eigenvalue of the matrix $\mathbf{A} \circ \mathbf{M}\left(s^{*}\right)$, and $\mathbf{w}$ and $\mathbf{v}$ are the corresponding right and left eigenvectors of $\mathbf{A}$ 。 $\mathbf{M}\left(s^{*}\right)$. Elasticities are calculated as

$$
\left(\frac{a_{i j}}{c^{*}}\right)\left(\frac{\partial c^{*}}{\partial a_{i j}}\right)
$$

The expressions given in (1)-(7) refer to a model that is set in a one-dimensional space, but the dispersal data were collected in two spatial dimensions. Since dispersal distances were pooled into discrete classes without regard for direction, we assumed that dispersal was radially symmetric and hence that the rate of spread was the same in every direction. Thus the measured dispersal kernels were two-dimensional histograms of the following form:

$$
k_{2}(r)= \begin{cases}f_{i} & \text { if } r_{i-1}<r<r_{i} \\ 0 & \text { otherwise }\end{cases}
$$

where $r=\sqrt{x^{2}+y^{2}}, 1 \leq i \leq \ell$, and the $r_{i}$ are the histogram bin edges. The appropriate one-dimensional kernel to use in formula (3) for this two-dimensional kernel is the marginal distribution:

$$
k(x)=\int_{-\infty}^{\infty} k_{2}\left(\sqrt{x^{2}+y^{2}}\right) d y .
$$

Lewis et al. (2005) have shown that the associated moment generating function is given by

$$
m(s)=\frac{2 \pi}{s} \sum_{i=1}^{\ell} f_{i}\left[r_{i} I_{1}\left(s r_{i}\right)-r_{i-1} I_{1}\left(s r_{i-1}\right)\right]
$$

where $I_{1}$ is the modified Bessel function of the first kind and first order (Abramowitz and Stegun 1970).

Invasion speed was calculated for each plot in burned and unburned heathland using their associated dispersal kernels and population projection matrices. Finally, in order to study the impact of fire on the relative importance of dispersal and demographic parameters in determining invasive spread of $M$. caerulea, dispersal and demographic parameters were combined in every possible way, and for each combination of parameters invasion speed was calculated for each plot separately and for the average demographic matrix across the four sites. All calculations were performed in MATLAB, Version 6.5. (MathWorks, Natick, Massachusetts, USA)

\section{RESUlts}

The seed dispersal distributions obtained from the germination experiment are shown in Fig. 2. Most seeds fell in the immediate neighborhood of the parent plant and only a very small fraction of seeds traveled further than $4 \mathrm{~m}$. Although seedling densities around parent plants were almost twice as high in the burned compared to the unburned site, the associated dispersal kernels showed very little differences (Fig. 2).

A total of 5111 individuals were monitored during the 4 -yr period. All populations $(n=8)$ were increasing. Population growth rates $(\lambda)$ calculated from the averaged matrices (Appendix A) varied between 1.773 and 2.561 (mean $=2.255, \mathrm{SD}=0.378)$ in the burned plots and between 1.177 and 1.311 (mean $=1.237$, SD $=0.055$ ) in the unburned plots (Fig. 3). For all sites, permutation tests revealed that growth rates were significantly larger in burned compared to unburned plots $(P<0.001)$.

Elasticity analysis showed that in the burned situation the life cycle stage that is most important in relation to its contribution to population growth rate was growth of juveniles to reproductive adults, whereas in the unburned plots survival of the largest individuals was most influential to population growth rate (Appendix B). The elasticity structure also differed largely 

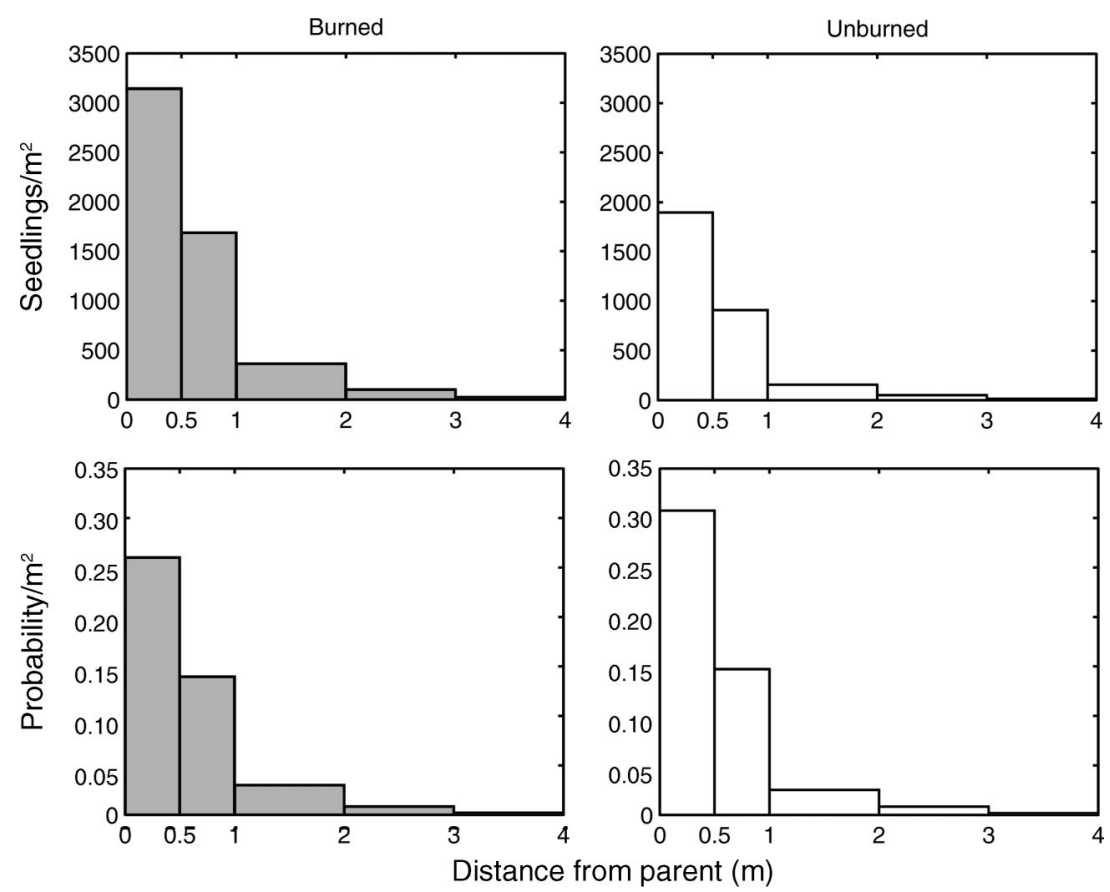

FIG. 2. Histograms of seedling densities at different distances from parent plants based on the seed germination experiment and the associated dispersal kernels.

between burned and unburned plots (Fig. 4). The composite elasticities for fecundity and the seedling stage were, on average, two times larger for burned than for unburned plots ( $22 \%$ vs. $10 \%$, respectively). Composite elasticities for reproductive adults, on the other hand, were much larger in the unburned than in the burned populations.

Invasion speed $\left(c^{*}\right)$ ranged from 0.5916 to 0.8502 $\mathrm{m} / \mathrm{yr}$ (mean $=0.7518, \mathrm{sD}=0.1141)$ in burned plots and from 0.2291 to $0.3034 \mathrm{~m} / \mathrm{yr}$ (mean $=0.2606$, SD $=0.0311$ ) in unburned plots (Fig. 5). When combining

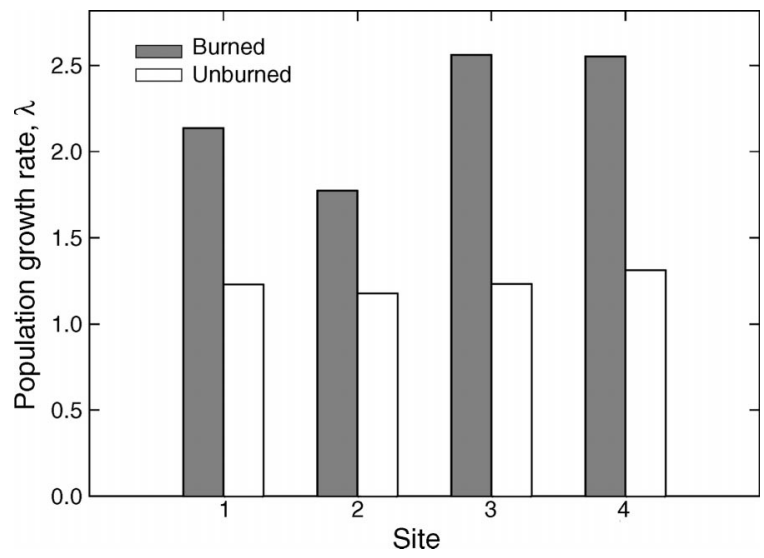

FIG. 3. Population growth rates calculated from the averaged population matrices of Molinia caerulea in four plots that were burned and four plots that were unburned (see Methods: Data analysis). dispersal kernels and population projection matrices from burned and unburned plots, it appeared that dispersal parameters were far less influential in determining invasive rates than demographic parameters (Table 1 ), as there was only an average increase of $2 \%$ in invasion speed when, irrespective of demographic parameters, dispersal kernels in unburned plots were replaced by dispersal kernels obtained in burned heath-

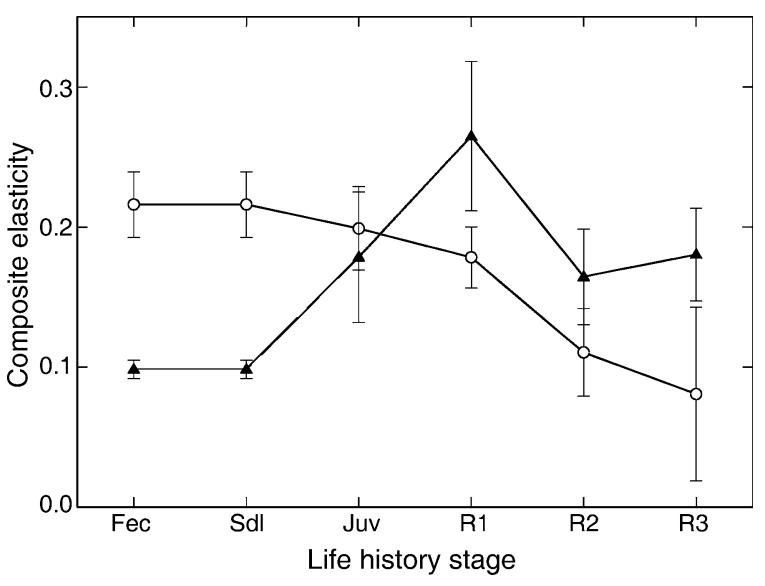

FIG. 4. Composite elasticities for fecundity and the fate of each stage for burned plots (open circles) and unburned plots (solid triangles). Error bars represent the standard deviation of four plots. Elasticities were combined by summing each column, excluding fecundity. Abbreviations: Fec, fecundity; Sdl, seedling; Juv, juvenile; R1, small reproductive adult; $\mathrm{R} 2$, medium reproductive adult; R3, large reproductive adult. 


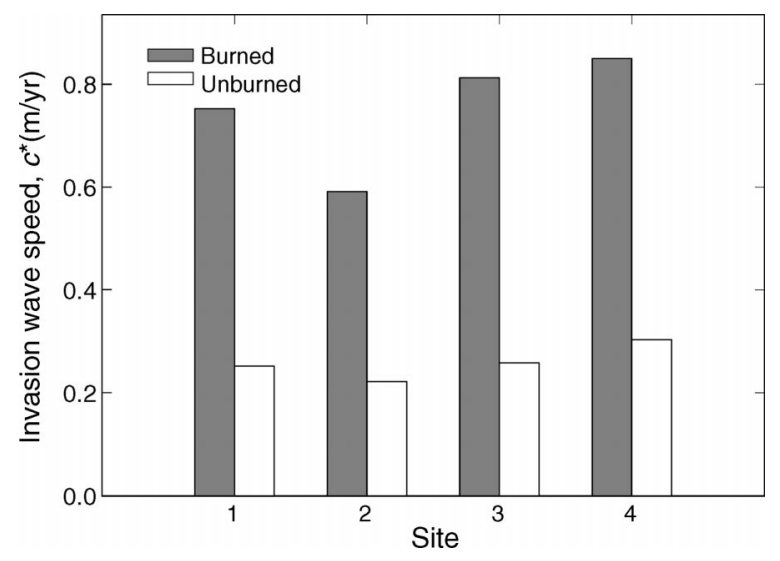

FIG. 5. Invasion speed, $c^{*}$, for Molinia caerulea in burned and unburned heathland using dispersal kernels of Fig. 2.

land. On the other hand, invasion speed dramatically increased when projection matrices from unburned heathland were replaced by those from burned heathland (Table 1).

Sensitivity matrices for $M$. caerulea in burned and unburned heathland show that in both cases invasion rate was most sensitive to changes in the transitions from seeds to large-class reproductive adults (Fig. 6). The elasticity matrix, on the other hand, shows that, on average, the largest proportional changes in invasion rate in burned plots are generated by changes in the growth of seedlings to juveniles and of juveniles to small-sized adults in burned plots. In unburned plots, however, there is no particular life cycle or transition that overwhelmingly dominates $c^{*}$, as elasticities are fairly uniformly distributed throughout the life cycle (Fig. 6). Compared to burned plots, survival of reproductive adults appeared to be more important in unburned plots.

As seen in Fig. 2 and Table 1, dispersal kernels did not significantly differ between the burned and unburned situation. Demographic parameters, however, did change (Appendix A), and it is this change in demography that is primarily responsible for the differences in the computed invasion rates. We therefore used a life table response experiment (LTRE) analysis to decompose the difference between invasion speeds of burned and unburned sites into contributions from differences in the entries in $\mathbf{A}$. The average demographic matrix in unburned years is

$$
\mathbf{A}^{(u)}=\left(\begin{array}{ccccc}
0 & 0 & 0.4485 & 4.1658 & 6.3630 \\
0.4933 & 0.5395 & 0 & 0 & 0 \\
0.0100 & 0.2998 & 0.7285 & 0.1415 & 0 \\
0 & 0.0070 & 0.2070 & 0.6123 & 0.0278 \\
0 & 0 & 0 & 0.2253 & 0.9722
\end{array}\right)
$$

and in burned years is

$$
\mathbf{A}^{(b)}=\left(\begin{array}{ccccc}
0 & 0 & 6.5055 & 17.4755 & 52.4338 \\
0.7993 & 0.0410 & 0 & 0 & 0 \\
0.0288 & 0.6568 & 0.3808 & 0 & 0 \\
0 & 0.0078 & 0.5388 & 0.4915 & 0 \\
0 & 0 & 0.0303 & 0.4993 & 1.0000
\end{array}\right)
$$

Using an average dispersal kernel estimated from both burned and unburned years in conjunction with these two matrices gives $c^{(u)}=0.3117 \mathrm{~m} / \mathrm{yr}$ as the projected invasion speed in the unburned situation and $c^{(b)}=$ $0.7947 \mathrm{~m} / \mathrm{yr}$ as the speed after burning. The first-order approximation to the difference in wave speed can be written as follows (Caswell et al. 2003):

$$
c^{(b)}-\left.c^{(u)} \approx \sum_{i, j}\left[a_{i j}^{(b)}-a_{i j}^{(u)}\right] \frac{\partial c}{\partial a_{i j}}\right|_{\left[\mathbf{A}^{(b)}+\mathbf{A}^{(u)}\right] / 2}
$$

and the matrix of contributions from the demographic differences is given by

$$
\begin{aligned}
{\left[\mathbf{A}^{(b)}-\mathbf{A}^{(u)}\right] \circ\left(\frac{\partial c}{\partial a_{i j}}\right) } & \\
& =\left(\begin{array}{ccccc}
0 & 0 & 0.1366 & 0.0513 & 0.0413 \\
0.0599 & -0.0240 & 0 & 0 & 0 \\
0.0194 & 0.0907 & -0.0209 & -0.0015 & 0 \\
0 & 0.0005 & 0.0522 & -0.0032 & -0.0002 \\
0 & 0 & 0.0104 & 0.0161 & 0.0004
\end{array}\right) .
\end{aligned}
$$

From this matrix, it can be concluded that the burned

TABLE 1. Invasion speed, $c^{*}$, of Molinia caerulea calculated from dispersal and demographic parameters of plots located in burned and unburned heathland at four sites.

\begin{tabular}{lll}
\hline \hline & \multicolumn{2}{c}{ Demography } \\
\cline { 2 - 3 } Dispersal & Unburned & Burned \\
\hline Unburned & & \\
Site 1 & 0.2519 & 0.7413 \\
Site 2 & 0.2291 & 0.5813 \\
Site 3 & 0.2581 & 0.8015 \\
Site 4 & 0.3034 & 0.8382 \\
ADM $\dagger$ & 0.3072 & 0.7866 \\
Burned & & \\
Site 1 & 0.2576 & 0.7541 \\
Site 2 & 0.2350 & 0.5916 \\
Site 3 & 0.2641 & 0.8128 \\
Site 4 & 0.3097 & 0.8502 \\
ADM $\dagger$ & 0.3139 & 0.7986 \\
\hline
\end{tabular}

Notes: Demographic parameters refer to the time-averaged transition matrices calculated for each pair of plots (one in burned heathland, one in unburned heathland). In total, four pairs of plots were studied. Dispersal parameters refer to the dispersal kernel calculated for plants located in burned and unburned heathland, respectively (see Methods: Data analysis).

$\dagger$ Invasion speed calculated from the average demographic matrix (ADM) across the four sites. 

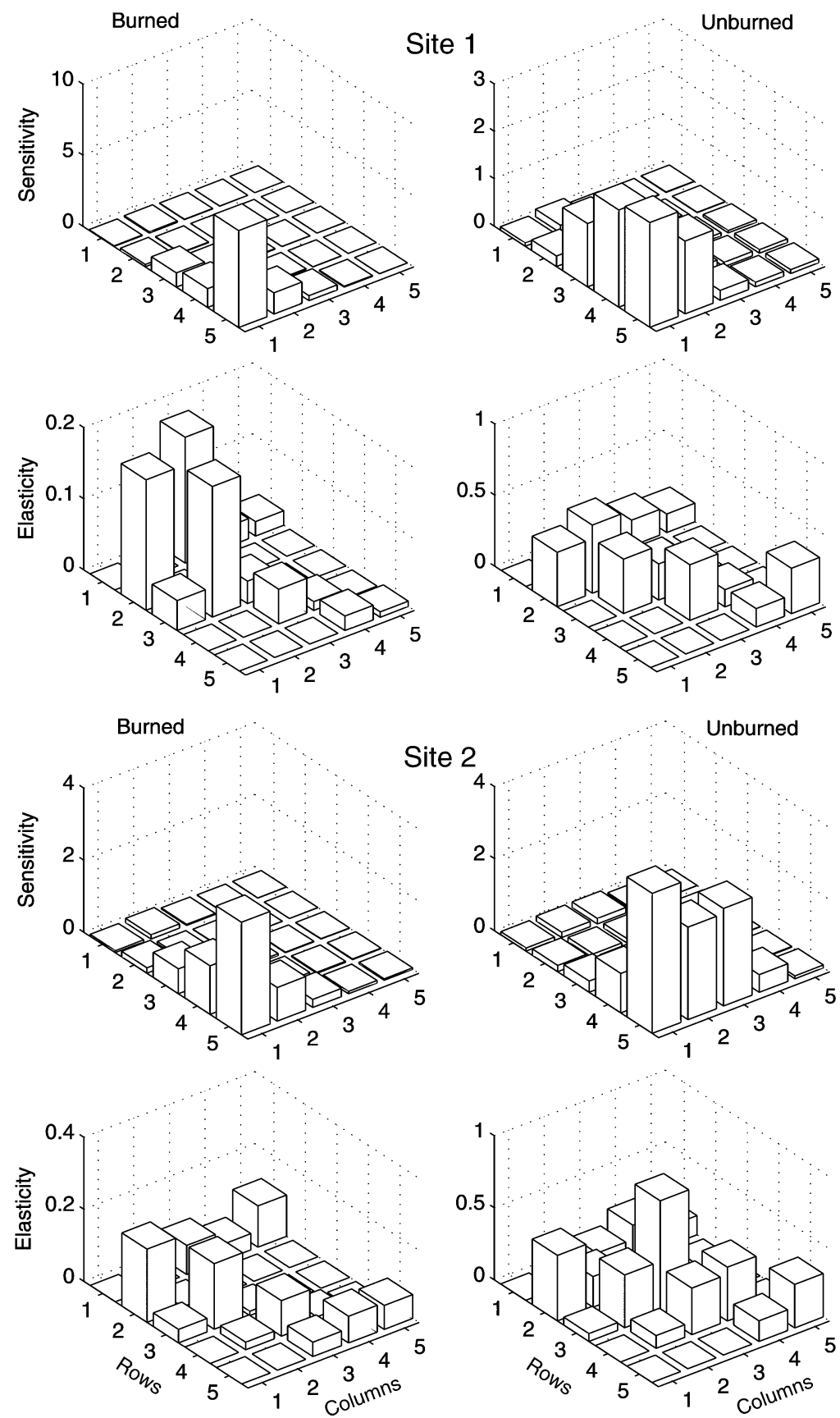

FIG. 6. Sensitivity and elasticity matrices of invasion speed, $c^{*}$, to changes in $a_{i j}$ for four plots in burned and four plots in unburned heathland. Rows and columns correspond to the matrix in Fig. 1 (see also Neubert and Caswell 2000).

population has an advantage in reproduction and recruitment (growth of seedlings and juveniles).

\section{DISCUSSION}

During the last decades, $M$. caerulea has invaded large areas of heathland in Western Europe (e.g., Hansen 1976, Berendse et al. 1994, Chambers et al. 1999). At present, the species is considered a major threat to heath- land conservation. Previous research (Grant et al. 1963, Todd et al. 2000, Marrs et al. 2004) had already suggested that fire had a beneficial impact on M. caerulea, but until now a mechanistic explanation for the increased abundance of $M$. caerulea after fire had not been provided. Using information on both dispersal distances and demography allowed us to assess the impact of fire on invasive spread of $M$. caerulea in dry heathland. 


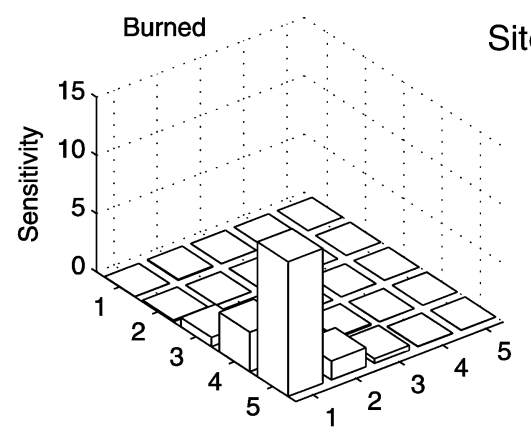

Site 3
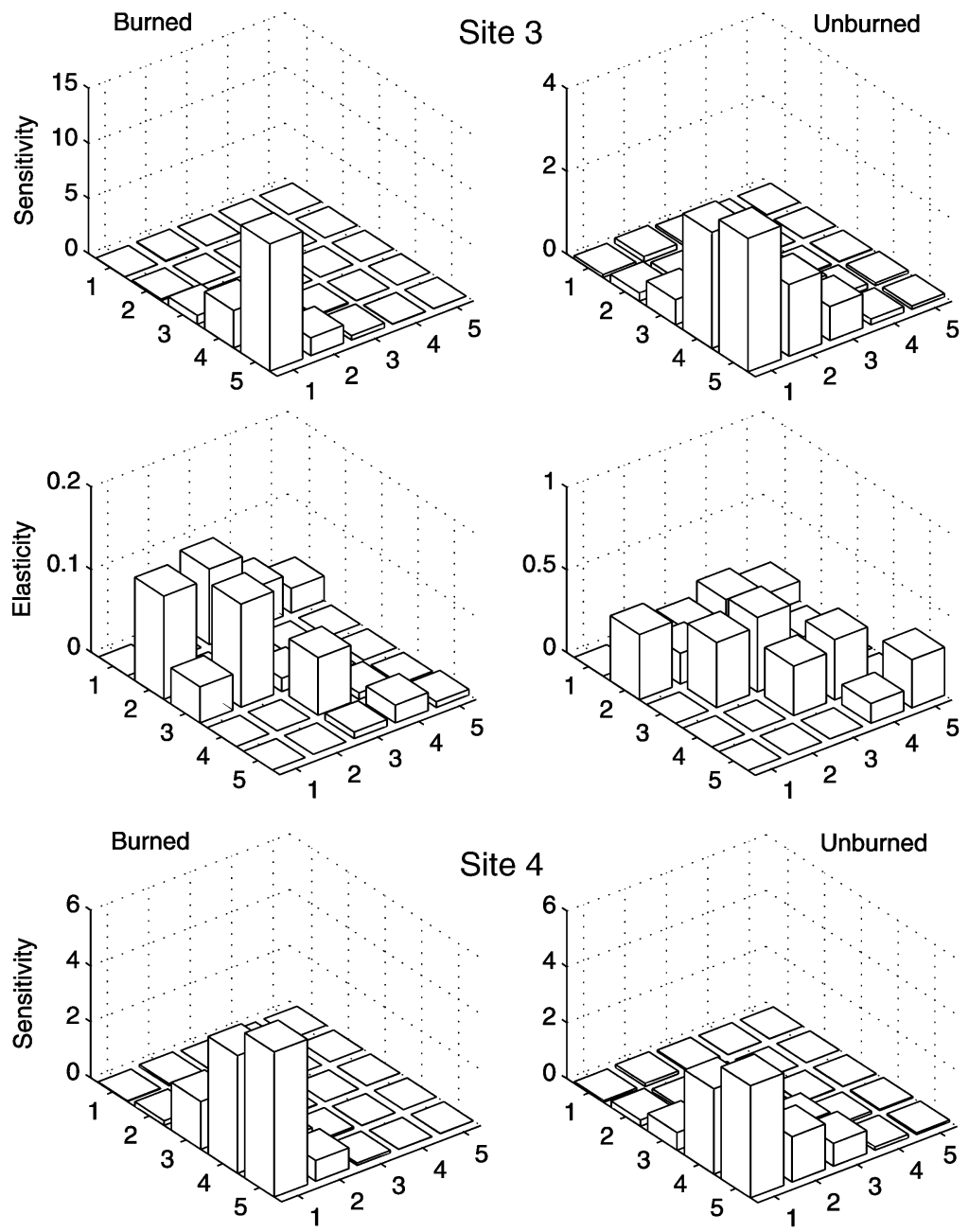

Site 4
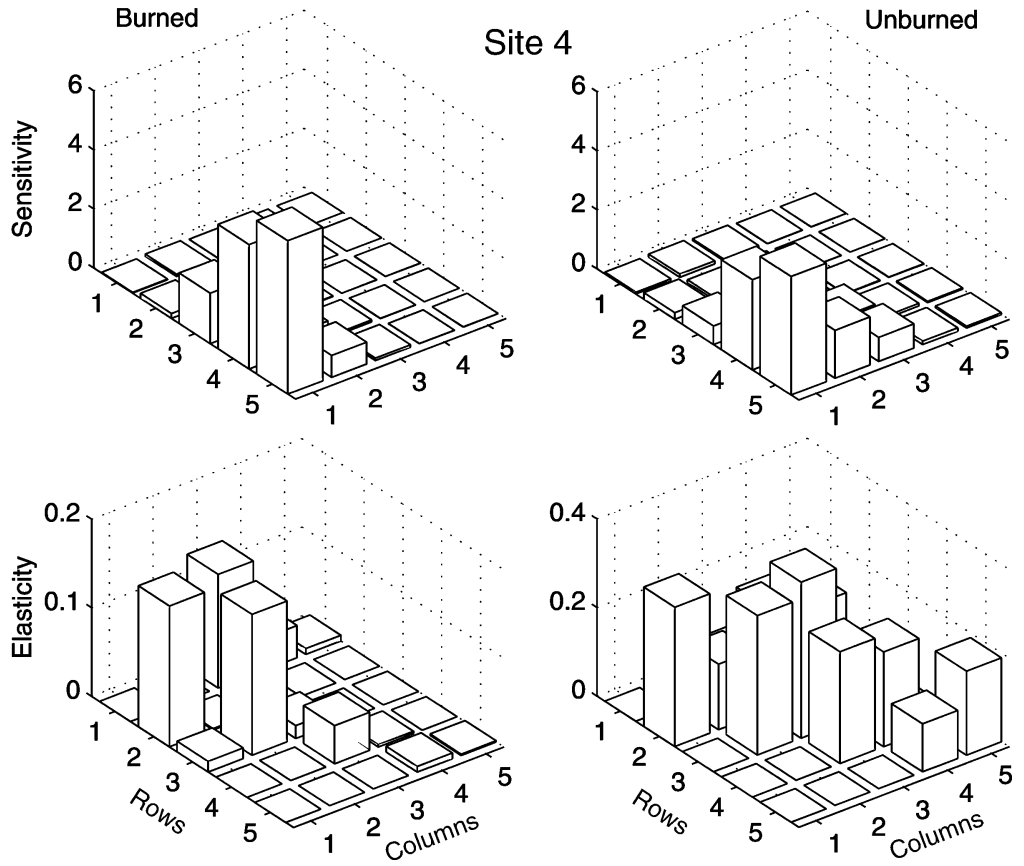

FIG. 6. Continued.

\section{Dispersal}

The spatial distribution of seeds about parent plants was typically leptokurtic. Distances traveled by most $M$. caerulea seeds were quite small as the mean dispersal distance was found to be $<1 \mathrm{~m}$. These results are in accordance with seed dispersal distances found for other grass species. For example, the mean seed dispersal distance of the perennial tussock grass $\mathrm{Hy}$ parrhenia diplandra was also around $1 \mathrm{~m}$ (Garnier and Dajoz 2001b, Garnier et al. 2002). Similar seed dis- persal distances as the ones observed for $M$. caerulea were also reported by Guàrdia et al. (2000) for the tussock forming grass Achnatherum calamagrostis and by Watkinson et al. (2000) for the annual grass Vulpia ciliata, respectively. Surprisingly, although mean total seed output per plant in the burned situation was nearly three times higher than in the unburned situation (Brys et al. 2005) and notwithstanding the fact that fire provoked sizeable increases in seedling densities, seed production hardly affected seed dispersal distances. 
Hence, the results point to low overall seed dispersal of $M$. caerulea both in burned and unburned heathland.

\section{Demographic changes following fire}

Although all the matrices analyzed gave projected rates of increase larger than one, indicating that $M$. caerulea populations increased both in unburned and burned heathland, population growth rates were, on average, two times higher in burned compared to unburned plots. This clearly demonstrates that fire has a pronounced, positive effect on the demography of $M$. caerulea. In line with the results presented here, Grant et al. (1963) and Todd et al. (2000) also observed that burning favored $M$. caerulea in British moorlands. In both cases, the species was found to rapidly recover after burning. Studies on other grass species have also shown beneficial effects of fire on population demography (e.g., Silva et al. 1991). Canales et al. (1994) even found growth rates that were four times larger in burned plots compared to unburned plots for the annual grass Andropogon brevifolius.

The much higher elasticities for fecundity and growth of the seedling stage in the burned compared to the unburned plots clearly demonstrate that fire induced a significant increase in seed germination and survival rates of $M$. caerulea. Indeed, two years after fire seedling recruitment was nearly six times higher in burned plots than in unburned plots and after four years seedling recruitment was still significantly higher in burned than in unburned heathland (results not shown). This can be explained in part by increased germination rates of seeds originating from plants growing in burned sites and in part by the increased seed production after fire (Brys et al. 2005). Furthermore, burning and the associated decrease in litter and increase in light penetration to the soil (Todd et al. 2000) may have created ideal conditions for germination. Despite higher seedling and juvenile densities, these conditions also resulted in lower mortality rates of seedlings and juveniles (data not shown). Using 10 years of demographic data, Menges and Quintana-Ascencio (2004) found similar decreases in composite elasticities for the seedling stage with time since fire, and increases in elasticities for stasis of the largest reproductive individuals.

\section{Spatial spread}

Although data on the spread of perennial tussock grass species are still rare, most studies assume initial seedling recruitment followed by prolonged vegetative reproduction (Suzuki et al. 1999). MacDonald and Lieffers (1991), for example, found extensive genetic variation in the perennial grass Calamagrostis canadensis, but no evidence for seedling recruitment was observed. In contrast, $M$. caerulea showed repeated seedling recruitment, which resulted in spatial spread of the species. Recent studies on other tussock grass species (e.g., Achnatherum calamagrostis [Guàrdia et al. 2000] and
Festuca rubra [Suzuki et al. 1999]) have reported similar results, indicating the importance of sexual reproduction in determining spatial spread of these grass species.

Furthermore, the results of this study have clearly shown that disturbances such as fire may largely affect invasive spread of plant species. This may be caused by altered dispersal distances, changes in vital rates, or both. In the case of $M$. caerulea, fire increased the spreading speed of $M$. caerulea by a factor of three. This was mainly the result of changes in demographic parameters rather than changes in dispersal parameters. Caswell et al. (2003) already demonstrated that differences in demography could be as important as differences in dispersal in determining invasion speed. Increased seed production, germination, and growth of seedlings and juveniles were the main factors contributing to the observed differences in invasion spread between burned and unburned plots, as the LTRE analysis clearly showed positive contributions for these life cycle transitions. Moreover, elasticity analysis of invasion speed pointed to fecundity and growth of seedlings as important determinants of invasive spread of M. caerulea after fire. Hence, our results point to sexual reproduction and repeated seedling recruitment as the main factors driving spatial spread of the species after fire.

\section{Implications for conservation}

One of the primary motivations of this study was to understand the rate of spread of $M$. caerulea in dry heathland communities and the factors influencing this spread in order to formulate management actions aiming to halt future invasions of the species. Analysis of invasion speed in both burned and unburned sites clearly demonstrated that large, unintended fires like the one studied here are detrimental for heathland conservation, as this fire clearly affected invasion spread of M. caerulea. In the long term, this may lead to absolute dominance of Molinia as the high productivity after fire (Brys et al. 2005) leads to higher litter production, which in turn may lead to a further competitive advantage of $M$. caerulea and increased fire probabilities due to the increased aboveground fuel availability. Given the observation that fire regimes are expected to change over the next decades in response to global warming and land use changes (e.g., Flannigan et al. 2000, Pausas 2004), this may have serious implications for heathland conservation. The Kalmthoutse Heide may be exemplary, since during the last three decades at least three large and intense fires (1976, 1996, and 1997) have burned substantial areas of the Kalmthoutse Heide and have led to an increased abundance of $\mathrm{Mol}$ inia. A similar increase in fire frequency has also been observed in other heathland areas in Belgium.

These observations urge for an absolute necessity to reduce the probability of future fires by decreasing litter accumulation and hence aboveground fuel build-up. 
Recent research has shown that the latter can be best achieved by grazing in late summer or by selective herbicide application (glyphosate; Milligan et al. 2003, Marrs et al. 2004). Further, the results of this study also cast doubt on the possible role of controlled burnings in reducing $M$. caerulea cover in heathlands. Previous research (Grant et al. 1963, Todd et al. 2000) has already suggested that burning was not effective in countering expansion of $M$. caerulea. In case a fire has burned large areas of heathland, it is absolutely necessary to reduce seed set after fire, as fecundity and growth of seedlings and juveniles were by far the most important determinants of invasive spread. This can be achieved by mowing down all seed producing plants before seed set. In this way, germination rates can be kept low, and invasion can be halted. The fact that, four years after burning, germination rates in burned heathland were still significantly higher than in unburned heathland indicates that at least several years of active management are required to halt invasion of the species after fire.

\section{ACKNOWLEDGMENTS}

The authors thank K. Molenberghs for permission to carry out all fieldwork at the Kalmthoutse Heide, and H. Caswell and $\mathrm{C}$. Hunter for helpful discussions. Two anonymous reviewers provided useful comments on an earlier version of this manuscript. This work was supported by the Flemish Fund for Scientific Research (FWO) to HJ, the U.S. National Science foundation (DEB-0235692, OCE-0083976), and the U.S. Environmental Protection Agency (R-8290891) to MGN. This manuscript is Woods Hole Oceanographic Institution contribution 11314 .

\section{Literature Cited}

Abramowitz, M., and I. Stegun. 1970. Handbook of mathematical functions. Dover, New York, New York, USA.

Aerts, R. 1993. Biomass and nutrient dynamics of dominant species from heathlands. Pages 51-84 in R. Aerts and G. W. Heil, editors. Heathlands: patterns and processes in a changing environment. Kluwer Academic Publishers, Dordrecht, The Netherlands.

Aerts, R., and H. de Caluwe. 1989. Aboveground productivity and nutrient turnover of Molinia caerulea along an experimental gradient of nutrient availability. Oikos 54:320324.

Berendse, F., M. Schmitz, and W. de Visser. 1994. Experimental manipulation of succession in heathland ecosystems. Oecologia 100:38-44.

Bruggink, M. 1993. Seed bank, germination, and establishment of ericaceous and gramineous species in heathlands. Pages 153-180 in R. Aerts and G. W. Heil, editors. Heathlands: patterns and processes in a changing environment. Kluwer Academic Publishers, Dordrecht, The Netherlands.

Brys, R., H. Jacquemyn, and G. de Blust. 2005. Fire increases aboveground biomass, seed production and recruitment success of Molinia caerulea in dry heathland. Acta Oecologica, in press.

Canales, J., M. C. Trevisan, J. F. Silva, and H. Caswell. 1994. A demographic study of an annual grass (Andropogon brevifolius Schwarz) in burnt and unburnt savanna. Acta Oecologica 15:261-273.

Caswell, H. 2000. Prospective and retrospective perturbation analyses: their roles in conservation biology. Ecology 81: 619-627.
Caswell, H. 2001. Matrix population models. Second edition. Sinauer, Sunderland, Massachusetts, USA.

Caswell, H., and T. N. Kaye. 2001. Stochastic demography and conservation of an endangered perennial plant (Lomatium bradshawii) in a dynamic fire regime. Advances in Ecological Research 32:1-51.

Caswell, H., R. Lensink, and M. G. Neubert. 2003. Demography and dispersal: life table response experiments for invasion speed. Ecology 84:1968-1978.

Chambers, F. M., D. Mauquoy, and P. A. Todd. 1999. Recent rise to dominance of Molinia caerulea in environmentally sensitive areas: new perspectives from palaeoecological data. Journal of Applied Ecology 36:719-733.

De Blust, G., and M. Slootmaekers. 1997. De Kalmthoutse Heide. Davidsfonds, Leuven, Belgium.

de Kroon, H., J. Plaisir, J. van Groenendael, and H. Caswell. 1986. Elasticity: the relative contribution of demographic parameters to population growth rates. Ecology 67:14271431.

Fagan, W. F., M. A. Lewis, M. G. Neubert, and P. van den Driessche. 2002. Invasion theory and biological control. Ecology Letters 5:148-157.

Flannigan, M. D., B. J. Stocks, and B. M. Wotton. 2000. Climate change and forest fires. The Science of the Total Environment 262:221-229.

Garnier, L. K. M., and I. Dajoz. 2001a. The influence of fire on the demography of a dominant grass species of West African savannas, Hyparrhenia diplandra. Journal of Ecology 89:200-208.

Garnier, L. K. M., and I. Dajoz. 2001b. Evolutionary significance of awn length in a clonal grass of fire-prone savannas. Ecology 82:1720-1733.

Garnier, L. K. M., J. Durand, and I. Dajoz. 2002. Limited seed dispersal and microspatial population structure of an agamospermous grass of West African savannahs, Hyparrhenia diplandra (Poaceae). American Journal of Botany 89:1785-1791.

Gimingham, C. 1972. Ecology of heathlands. Chapman and Hall, London, UK.

Grant, S. A., R. F. Hunter, and C. Cross. 1963. The effect of muirburning Molinia-dominated communities. Journal of the British Grassland Society 18:249-257.

Grime, J. P., G. Mason, A. V. Curtis, J. Rodman, S. R. Band, M. A. G. Mowforth, A. M. Neal, and S. Shaw. 1981. A comparative study of germination characteristics in a local flora. Journal of Ecology 69:1017-1059.

Guàrdia, R., J. Raventós, and H. Caswell. 2000. Spatial growth and population dynamics of a perennial tussock grass (Achnatherum calamagrostis) in a badland area. Journal of Ecology 88:950-963.

Hansen, K. 1976. Ecological studies in Danish heath vegetation. Dansk Botanisk Archiv 31:7-116.

Horn, R. A., and C. R. Johnson. 1985. Matrix analysis. Cambridge University Press, Cambridge, UK.

Kaye, T. N., K. L. Pendergrass, K. Finley, and J. B. Kauffman. 2001. The effect of fire on the population viability of an endangered prairie plant. Ecological Applications 11:13661380 .

Lamont, B. B., and D. Wiens. 2003. Are seed set and speciation rates always low among species that resprout after fire, and why? Evolutionary Ecology 17:277-292.

Lewis, M. A., M. G. Neubert, H. Caswell, J. S. Clark, and K. Shea. 2005. A guide to calculating discrete-time invasion rates from data. In M. W. Cadotte, S. M. McMahon, and T. Fukami, editors. Conceptual ecology and invasions biology: reciprocal approaches to nature. Kluwer Academic Press, in press.

Limpens, J., F. Berendse, and H. N. Klees. 2003. N deposition affects $\mathrm{N}$ availability in interstitial water, growth of Sphag- 
num and invasion of vascular plants in bog vegetation. New Phytologist 157:339-347.

Lui, R. 1989. Biological growth and spread modeled by systems of recursions. I. Mathematical theory. Mathematical Biosciences 93:269-295.

MacDonald, S. E., and V. J. Lieffers. 1991. Population variation, outcrossing, and colonization of disturbed areas by Calamagrostis canadensis: evidence from allozyme analysis. American Journal of Botany 78:1123-1129.

Marrs, R. H., J. D. P. Phillips, P. A. Todd, J. Ghorbani, and M. G. Le Duc. 2004. Control of Molinia caerulea on upland moors. Journal of Applied Ecology 41:398-411.

McConnell, K., and E. S. Menges. 2002. Effects of fire and treatments that mimic fire on the Florida endemic scrub buckwheat (Eriogonum longifolium Nutt. var. gnaphalifolium Gand.). Natural Areas Journal 22:194-201.

Menges, E. S., and R. W. Dolan. 1998. Demographic viability of populations of Silene regia in midwestern prairies: relationships with fire management, genetic variation, geographic location, population size and isolation. Journal of Ecology 86:63-78.

Menges, E. S., and P. F. Quintana-Ascencio. 2004. Population viability with fire in Eryngium cuneifolium: deciphering a decade of demographic data. Ecological Monographs 74: 79-99.

Milligan, A. L., P. D. Putwain, E. S. Cox, J. Ghorbani, M. G. Le Duc, and R. H. Marrs. 2003. Developing an integrated land management strategy for the restoration of moorland vegetation on Molinia caerulea-dominated vegetation for conservation purposes in upland Britain. Biological Conservation 119:371-385.

Nathan, R., and H. C. Muller-Landau. 2000. Spatial patterns of seed dispersal, their determinants and consequences for recruitment. Trends in Ecology and Evolution 15:278-285.

Neubert, M. G., and H. Caswell. 2000. Demography and dispersal: calculation and sensitivity analysis of invasion speed for structured populations. Ecology 81:16131628 .

Neubert, M. G., M. Kot, and M. A. Lewis. 2000. Invasion speeds in fluctuating environments. Proceedings of the Royal Society of London Series B-Biological Sciences 267:1603-1610.
Neubert, M. G., and I. M. Parker. 2004. Projecting rates of spread for invasive species. Risk Analysis 24:817-831.

Noble, I. R., and R. O. Slatyer. 1980. The use of vital attributes to predict successional changes in plant communities subject to recurrent disturbances. Vegetatio 43:5-21.

Parker, I. M. 2000. Invasion dynamics of Cytisus scoparius: a matrix model approach. Ecological Applications 10:726743.

Pausas, J. G. 2004. Changes in fire and climate in the eastern Iberian Peninsula (Mediterranean basin). Climatic Change 63:337-350.

Quintana-Ascencio, P. F., E. S. Menges, and C. W. Weekley. 2003. A fire-explicit population viability analysis of $\mathrm{Hy}$ pericum cumulicola in Florida rosemary scrub. Conservation Biology 17:433-449.

Satterthwaite, W. H., E. S. Menges, and P. F. Quintana-Ascencio. 2002. Assessing scrub buckwheat population viability in relation to fire using multiple modeling techniques. Ecological Applications 12:1672-1687.

Silva, J. G., J. Raventos, H. Caswell, and M. C. Trevisan. 1991. Population responses to fire in a tropical savanna grass Andropogon semiberbis: a matrix model approach. Journal of Ecology 79:345-356.

Suzuki, J., T. Herben, F. Krahulec, and T. Hara. 1999. Size and spatial pattern of Festuca rubra genets in a mountain grassland: its relevance to genet establishment and dynamics. Journal of Ecology 87:942-954.

Taylor, K., A. P. Rowland, and E. H. Jones. 2001. Molinia caerulea (L.) Moench. Journal of Ecology 89:126-144.

Todd, P. A., J. D. P. Phillips, P. D. Putwain, and R. H. Marrs. 2000. Control of Molinia caerulea on moorland. Grass and Forage Science 55:181-191.

Tomassen, H. B. M., A. J. P. Smolders, L. P. M. Lamers, and J. G. M. Roelofs. 2003. Stimulated growth of Betula pubescens and Molinia caerulea on ombothrophic bogs: role of high levels of atmospheric nitrogen deposition. Journal of Ecology 91:357-370.

Watkinson, A. R., R. P. Freckleton, and L. Forrester. 2000. Population dynamics of Vulpia ciliata: regional, patch and local dynamics. Journal of Ecology 88:10121029.

\section{APPENDIX A}

A table showing the averaged transition matrices for each site in burned and unburned heathland is available in ESA's Electronic Data Archive: Ecological Archives A015-063-A1.

\section{APPENDIX B}

A table showing the elasticity values of averaged population projection matrices of four sites in burned and four sites in unburned heathland is available in ESA's Electronic Data Archive: Ecological Archives A015-063-A2. 